\title{
咜藏温度对鲜枸杞类胡萝卜素和氨基酸的影响 及调控机制
}

周宜洁 ${ }^{1}$, 李 新 $^{2}$, 马三梅 ${ }^{2}$, 曾少华 ${ }^{1}$, 王瑛 ${ }^{1}$, 蒋跃明 ${ }^{1}$, 屈红霞 ${ }^{*}$

1. 中国科学院华南植物园, 广州 510650 ;

2. 暨南大学生物工程学系, 广州 510632

*联系人, E-mail: q-hxia@scbg.ac.cn

2020-12-30 收稿, 2021-02-11 修回, 2021-02-22 接受, 2021-02-23 网络版发表

国家重点研发计划(2016YFD0400904)、国家自然科学基金(31770334)、广州市民生科技攻关计划(201803020028)和宁夏农业综合开发科技推 广项目(NTKJ2018-01-03)资助

摘要 本研究探讨了 4 和 $-4^{\circ} \mathrm{C}$ 贮藏对鲜枸杞类胡萝卜素水平、类胡萝卜素合成、存储、降解相关基因以及氨基酸 代谢相关基因表达的调控作用。结果表明, $-4^{\circ} \mathrm{C}$ 贮藏的枸杞果实中 $\beta$-胡萝卜素、玉米黄素和玉米黄素双棕桐酸酯 含量显著高于 $4{ }^{\circ} \mathrm{C}$, 贮藏末期玉米黄素双棕榈酸酯含量比 $4{ }^{\circ} \mathrm{C}$ 贮藏高 $42.14 \%$. 枸杞果实低温贮藏过程中类胡萝卜素 合成、存储和降解相关基因普遍上调表达，特别是类胡萝卜素裂解酶基因 $L b C C D 4$ 在抄藏过程中表达量升高超过 70 倍. $4{ }^{\circ} \mathrm{C}$ 贮藏枸杞果实类胡萝卜素合成基因表达显著高于 $-4{ }^{\circ} \mathrm{C}$, 但是存储蛋白基因 LbHSP $21 、 L b O R 2$ 表达极显著 低于 $-4^{\circ} \mathrm{C}$, 降解酶基因 $L b N C E D 6 、 L b C C D 1 、 L b C C D 4$ 则极显著高于 $-4^{\circ} \mathrm{C}$, 可能是导致其类胡萝卜素含量低于 $-4^{\circ} \mathrm{C}$ 的主要原因. 另一方面, $4^{\circ} \mathrm{C}$ 贮藏上调脯氨酸合成相关的 $L b O A T$ 表达、维持脯氨酸降解相关的 $L b P r o D H$ 在较低水平, 从而有利于脯氨酸的积累. 上述结果说明, $-4^{\circ} \mathrm{C}$ 贴藏更有利于枸杞类胡萝卜素的积累、保持较好的营养品质, 并延 缓果实衰老劣变.

关键词贮藏温度, 玉米黄素双棕桐酸酯, 类胡萝卜素, 氨基酸, 代谢, 调控

枸杞(Lycium barbarum L.) 是茄科枸杞属多年生落 叶灌木．枸杞果实富含多糖、类胡萝卜素、类黄酮、 维生素、氨基酸等营养物质和生物活性物质, 具有清 肝、明目、补气，提高免疫力，预防心血管疾病、癌症 等作用, 因此被认为是一种“超级食品”, ${ }^{[1]}$.

枸杞果实的色泽主要由枸杞果实中类胡萝卜素的 种类和含量决定. 枸杞果实中主要的类胡萝卜素成分 为玉米黄素双棕㭣酸酯、玉米黄素和 $\beta$-胡夢卜素. 其 中, 玉米黄素双棕㭣酸酯(zeaxanthin dipalmitate)是枸 杞中最具特征性的类胡萝卜素, 其含量占枸杞类胡萝
卜素总量的 $80 \%$ 以上，因此又被称为“枸杞红素”, [2]. 玉 米黄素双棕㭣酸酯因其抗氧化和抗视网膜病变、黄斑 变性、非酒精性脂肪肝、急性肝损伤、肝癌等疾病的 作用, 近年来备受关注 ${ }^{[3,4]}$. 目前植物中类胡萝卜素的生 物合成途径已经比较清晰, 玉米黄素双棕㭣酸酯的合 成在类胡萝卜素下游 $\beta$-胡萝卜素分支途径中, $\beta$-胡萝卜 素和玉米黄素是玉米黄素双棕㭣酸酯合成的上游物质. 因此，该下游分支合成途径可能是枸杞果实类胡萝卜 素代谢的主要途径; 并且, 枸杞果实类胡萝卜素水平受 合成、存储和降解酶基因的共同调控 ${ }^{[5]}$.

引用格式: 周宜洁, 李新, 马三梅, 等. 贮藏温度对鲜枸杞类胡萝卜素和氨基酸的影响及调控机制. 科学通报, 2022, 67: 385-395 
氨基酸是枸杞果实的重要营养成分和药效成分, 其种类和含量是决定枸杞品质的关键因素 ${ }^{[6,7]}$. 枸杞中 的游离氨基酸可以直接被人体吸收利用，也可以合成 蛋白质，参与维持机体新陈代谢、生长、繁殖以及免

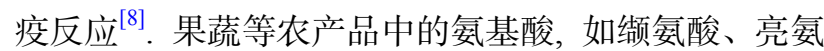
酸、异亮氨酸、蛋氨酸、苯丙氨酸和丙氨酸的合成或 分解代谢形成的嗅感物质和味感物质，使果蔬呈现特 有的香味/甜味. 其他氨基酸作为这些产生气味的氨基 酸的前体物质发挥作用, 例如天冬氨酸作为前体物质 参与多种氨基酸的合成，包括赖氨酸、蛋氨酸、苏氨

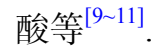

枸杞在干制过程中往往伴随着营养成分，如类胡 萝卜素、氨基酸等的流失 ${ }^{[12]}$. 相比干枸杞, 不经任何处 理的新鲜枸杞能够更好地保留枸杞中的营养成分. 近 年来，随着消费者对食物的营养、健康以及自然属性 的更高追求, 鲜食枸杞越来越受欢迎 ${ }^{[13]}$. 但是枸杞鲜果 由于其结构的特殊性(皮薄质嫩、中空、含水量高), 采 后极易发生糖化和腐烂，在室温下咜藏1 2 d即失去商 品价值 ${ }^{[14]}$. 枸杞鲜果的穴藏保鲜不仅决定鲜食枸杞产 品质量，同时对降低制干过程中油果(油籽)率，提高干 制枸杞产品质量具有重要意义。低温捾藏可以降低果 蔬呼吸速率、降低物质消耗、抑制微生物繁殖、延缓 腐烂, 是农产品保鲜最有效的途径 ${ }^{[15,16]}$.

本研究在前期工作 ${ }^{[17]}$ 基础上，以“宁杞9号”鲜枸杞 为实验材料, 研究不同咜藏温度 $\left(4\right.$ 和 $\left.-4^{\circ} \mathrm{C}\right)$ 对鲜枸杞 $\beta$ 胡萝卜素、玉米黄素、玉米黄素双棕㭣酸酯水平，类 胡萝卜素合成、存储、降解相关基因以及氨基酸代谢 相关基因表达的影响，以期探讨败藏温度对鲜枸杞类 胡萝卜素和游离氨基酸的调控作用, 明确其营养品质 衰变规律, 为鲜枸杞的穴藏保鲜提供理论依据.

\section{1 材料和方法}

\section{1 植物材料}

实验材料为宁夏特色大果型枸杞品种“宁杞9号”, 商业采收成熟度 $(80 \%$ $90 \%$ 成熟)，7月中旬采自中国科 学院西北生物农业中心枸杞种植园(银川市平吉堡). 果 实采收后，在 $13.5 \mathrm{~h}$ 内 $\left(\right.$ 平均温度 $\left.26.5^{\circ} \mathrm{C}\right)$ 空运到广州的实 验室. 挑选大小一致、色泽均一、无机械损伤、无肉眼 可见病斑的枸杞果实, 用自来水漂洗, 晾干, 装人塑料饭 盒, 每盒 $150 \mathrm{~g}$, 共 24 盒, 分别咜藏于 4 和 $-4^{\circ} \mathrm{C}$ 冷库, 每个温 度放置 12 盒. 在 $0 、 7 、 14 、 21 \mathrm{~d}$ 每个温度随机选取 3 盒,
观察拍照, 样品冻存于 $-80^{\circ} \mathrm{C}$ 用于后续实验. 每个实验设 置3个生物学重复, 结果取 3 次实验数据的平均值.

\section{2 外观品质分级}

枸杞果实按外观品质由好到差分为 5 级: 0 级, 无明 显皱缩、糖化、霉变斑点; 1级, 可见皱缩、糖化, 无明 显霉变斑点, 或霉变斑点直径 $d \leqslant 1 \mathrm{~mm} ; 2$ 级, 霉点 $1<d$ $\leqslant 2 \mathrm{~mm}$, 轻度皱缩、糖化; 3 级, 霉点 $2<d \leqslant 4 \mathrm{~mm}$, 中度 皱缩、糖化; 4级, 霉点 $d>4 \mathrm{~mm}$, 严重皱缩、糖化. 其 中, 2 4级果被认为无商品价值(图S1).

\section{3 玉米黄素、 $\beta$-类胡萝卜素和玉米黄素双棕榈酸 酯含量测定}

参照李新 ${ }^{[17]}$ 的研究方法, 采用非㿝化的方法提取 枸杞果实类胡萝卜素. 将干燥的类胡萝卜素提取物加 人流动相至 $10 \mathrm{~mL}$, 用 $0.45 \mu \mathrm{m}$ 注射器过滤. 用高效液相 色谱(HPLC)分析类胡萝卜素、玉米黄质和玉米黄素双 棕桐酸酯含量. 检测器为二极管阵列检测器(PDA), 样 品经 $\mathrm{C} 18$ 反相柱 $(25 \mathrm{~cm} \times 4.6 \mathrm{~mm}$, 粒径 $5 \mu \mathrm{m})$ 纯化. 流动 相由甲醇:乙腈:二氯甲烷:正己烷 $=15: 40: 20: 20$ (体积比) 组成, 柱温 $30^{\circ} \mathrm{C}$, 流速为 $1 \mathrm{~mL} / \mathrm{min}$, 检测波长为 $450 \mathrm{~nm}$. 采用玉米黄素和 $\beta$-胡萝卜素标准品绘制标准曲线, 计 算枸杞果实中玉米黄素和 $\beta$-类胡萝卜素含量.

玉米黄素双棕㭣酸酯的定量分析参照Karioti等

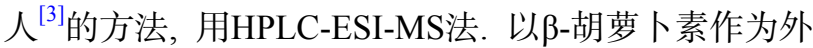
标物制作标准曲线，结果用分子量校正系数(玉米黄素 双棕榈酸酯的分子量 1045.8 与 $\beta$-胡萝卜素的分子量 536.8的比值)进行校正.

\subsection{RNA提取和基因表达分析}

使用总RNA提取试剂盒(Magen，中国)从不同温 度、不同它藏时间的枸杞果实中提取总RNA. 提取的 RNA用无RNase的DNase I(TaKaRa，日本)在 $37^{\circ} \mathrm{C}$ 处理 $30 \mathrm{~min}$, 以去除基因组DNA. 采用NanoDrop检测RNA质 量, 采用RNA凝胶电泳检测RNA纯度. 第一链cDNA使 用PrimeScript第一链cDNA合成试剂盒(TaKaRa，日本) 合成.

本研究所用基因序列主要参考刘永亮 ${ }^{[18]}$ 的研究. 利用Primer 5.0软件，根据目标基因全长序列设计苂光 定量引物(表S1). 采用枸杞Actin作为内参基因. 采用 Tecan SparkTM Multi-function Microwell Plate Detector (Dobio, 上海)测定合成的cDNA含量. 以cDNA为模板, 
采用TaKaRa公司的TB Green ${ }^{\circledR}$ Premix Ex Taq (Tli RNaseH Plus)试剂盒(TaKaRa，日本)进行qRT-PCR扩 增. 所用仪器为 $A B I 7500$ 菼光定量PCR仪, 采用 $2^{-\triangle \triangle C_{\mathrm{T}}}$ 法分析基因的相对表达水平. 本研究中所有 qRT-PCR 步骤均符合Minimum Information for Publication of Quantitative Real-Time PCR Experiments(MIQE)规范.

\section{5 数据分析}

使用Excel 2010进行初步数据统计, 使用SPSS Statistics 13软件进行差异显著性分析, 利用Sigmaplot 12.5 软件进行绘图.

\section{2 实验结果}

\section{1 玉米黄素、 $\beta$-类胡萝卜素和玉米黄素双棕㭣酸 酯含量}

枸杞果实从变色期开始逐渐积累玉米黄素直至果 实成熟. 在 4 和 $-4^{\circ} \mathrm{C}$ 捾藏过程中玉米黄素含量总体呈上 升趋势(图1(a)). 在第 7 天, $4^{\circ} \mathrm{C}$ 败藏的枸杞玉米黄素含量 高于 $-4^{\circ} \mathrm{C}$ 败藏，败藏 $14 \mathrm{~d}$ 后 $-4^{\circ} \mathrm{C}$ 穴藏的枸杞果实玉米 黄素含量始终高于 $4^{\circ} \mathrm{C}$ 的果实. 败藏末期, $-4^{\circ} \mathrm{C}$ 败藏的 枸杞果实玉米黄素从 $4.9 \pm 0.2 \mu \mathrm{g} / \mathrm{g}$ 上升到 $10.4 \pm 0.1 \mu \mathrm{g} / \mathrm{g}$, 而 $4^{\circ} \mathrm{C}$ 咜藏仅为 $8.0 \pm 0.2 \mu \mathrm{g} / \mathrm{g}$ ，二者之间差异显著 $(P<0.05) .-4$ 和 $4^{\circ} \mathrm{C}$ 梡藏 $21 \mathrm{~d}$ 枸杞玉米黄素含量分别增 加了 $112.2 \%$ 和 $63.3 \%$, 说明 $-4{ }^{\circ} \mathrm{C}$ 败藏显著增加枸杞果实 玉米黄素的积累.

枸杞采后 $4^{\circ} \mathrm{C}$ 败藏初期 $\beta$-胡萝卜素含量稍有增加, 在第 7 天达到峰值, 此后持续下降(图 1(b)). 但 $-4^{\circ} \mathrm{C}^{\circ}$ 㶓 的枸杞果实在咜藏 $14 \mathrm{~d}$ 时 $\beta$-胡萝卜素仍保持较高的水 平 $\left(\right.$ 比 $4^{\circ} \mathrm{C}$ 败藏高 $16.67 \%$, 差异显著), 说明 $-4^{\circ} \mathrm{C}$ 败藏可
以显著延缓枸杞果实 $\beta$-胡萝卜素的降解.

新鲜采摘的枸杞果实玉米黄素双棕榈酸酯含量为 $340.6 \pm 33.7 \mu \mathrm{g} / \mathrm{g}$, 约占总类胡萝卜素含量的 $85.75 \%{ }^{[17]}$. 在䛎藏过程中玉米黄素双棕㭣酸酯的含量呈先降后升 的趋势. 4 和 $-4^{\circ} \mathrm{C}$ 栬藏 $7 \mathrm{~d}$ 玉米黄素双棕㭣酸酯含量均降 到最低水平, 分别比咜藏前降低 $36.3 \%$ 和 $48.6 \%$, 差异显 著(图1(c)). 此后, $-4^{\circ} \mathrm{C}$ 只藏枸杞玉米黄素双棕㭣酸酯含 量讯速上升, 败藏末期, $-4^{\circ} \mathrm{C}$ 败藏的枸杞果实玉米黄素 双棕榈酸酯含量高达 $593.5 \pm 52.2 \mu \mathrm{g} / \mathrm{g}$ ，比 $4^{\circ} \mathrm{C}$ 败藏的枸 杞高 $42.14 \%$ ，差异极显著 $(P<0.01)$ ，表明 $-4{ }^{\circ} \mathrm{C}$ 败藏显著 增加枸杞果实玉米黄素双棕㭣酸酯的积累.

\section{2 类胡萝卜素合成途径关键酶基因表达}

类胡萝卜素的合成受多种关键酶基因的共同催化， 其中 1-脱氧木酮糖-5-磷酸合成酶(DXS) 是甲羟戊酸 MEP途径中第一个关键酶 ${ }^{[19]}$. 如图2所示, $L b D X S 1$ 和 $L b D X S 2$ 在它藏前期表达均显著上调。在整个咜藏过程 中 $4^{\circ} \mathrm{C}^{\circ}$ 藏的枸杞果实的 $L b D X S 1$ 表达量始终高于 $-4^{\circ} \mathrm{C}$. 在 $4^{\circ} \mathrm{C}$ 䛎藏条件下其表达量在 $14 \mathrm{~d}$ 达到峰值 $(16.6 \pm 2.5)$, 随之迅速下降; 而在 $-4^{\circ} \mathrm{C}$ 聍藏条件下，LbDXS2 表达量 在 $7 \mathrm{~d}$ 达到峰值，比 $4^{\circ} \mathrm{C}$ 咜藏提前了 $7 \mathrm{~d}$. 在败藏第 14 天 时， $L b D X S 2$ 基因的表达量在 4 和 $-4^{\circ} \mathrm{C}$ 下相比穴藏初期 分别提高了 17 和5倍, 二者存在极显著差异 $(P<0.01)$.

八氢番茄红素合成酶(PSY)、八氢番茄红素脱氢

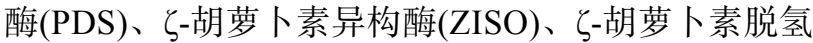
酶(ZDS)和类胡萝卜素异构酶(CRTISO)是类胡萝卜素 合成途径上游关键合成酶 ${ }^{[20]}$. 从图2中可以看出，这些 基因在穴藏过程中均呈现先升高后降低的趋势; 并且, 除 $L b Z D S$ 以外, $4^{\circ} \mathrm{C}$ 败藏条件下基因的表达量均显著高 于 $-4^{\circ} \mathrm{C}$. 此外, $L b C R T I S O$ 基因上调表达的增幅最为突
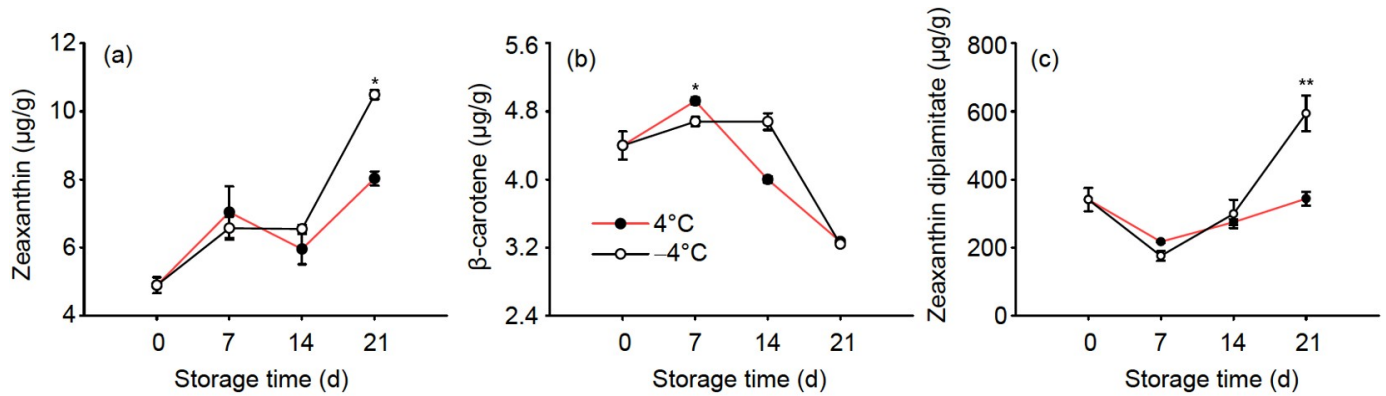

图 1 (网络版彩色)不同只藏温度鲜枸杞玉米黄素、 $\beta$-类胡萝卜素和玉米黄素双棕榈酸酯的含量. (a) 玉米黄素含量; (b) $\beta$ 类胡夢卜素含量; (c) 玉米黄素双棕㭣酸酯含量. “*”、“**”分别表示同一败藏时间不同则藏温度之间差异显著 $(P<0.05)$ 或极显著 $(P<0.01)$, 下同

Figure 1 (Color online) Contents of zeaxanthin, $\beta$-carotenoid and zeaxanthin dipalmitate, in fresh Goji berry during storage at different temperatures (a) Contenst of zeaxanthin; (b) contents of $\beta$-carotenoid; (c) contents of zeaxanthin dipalmitate. "** and "**" indicated that there was significant difference $(P<0.05)$ or extremely significance $(P<0.01)$ between different storage temperatures at the same storage time, the same below 

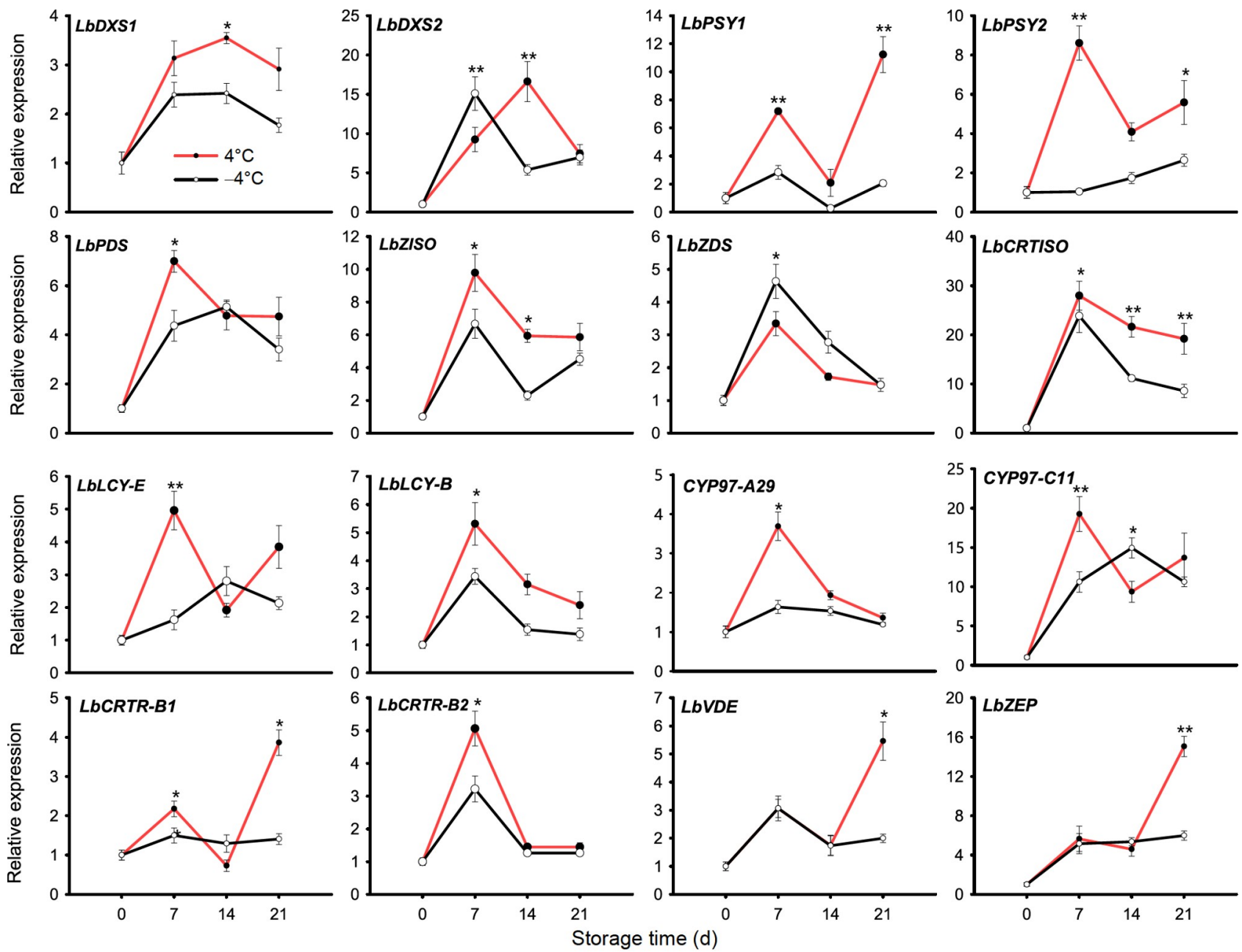

图 2 (网络版彩色)不同少藏温度鲜枸杞类胡萝卜素合成途径关键酶基因的表达. DXS1, 1-脱氧木酮糖-5-磷酸合成酶1基因; DXS2, 1-脱氧木酮

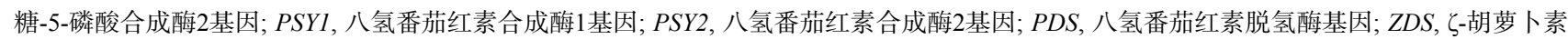
脱氢酶基因; $C R T I S O$, 类胡萝卜素异构酶基因; $L C Y-E$, 番茄红素 $\varepsilon$-环化酶基因; $L C Y-B$, 番茄红素 $\beta$ 环化酶基因; $C Y P 97-A 29$, 细胞色素P450 $\alpha$ 环羟 化酶基因; $C Y P 97-C 11$, 细胞色素P450 \&环差化酶基因; $C R T R-B 1, \beta$-胡萝卜素羟化酶基因1基因; $C R T R-B 2, \beta$-胡萝卜素差化酶基因2基因; ZEP, 玉 米黄素环氧化酶基因; $V D E$, 紫黄质脱环氧酶基因

Figure 2 (Color online) Gene expression of key enzymes in carotenoid biosynthesis pathway in fresh Goji berry during storage at different temperatures. DXS1, 1-deoxy-D-xylulose 5-phosphate-synthase 1 gene; DXS2, 1-deoxy-D-xylulose 5-phosphate-synthase 2 gene; PSY1, phytoene synthase 1 gene; $P S Y 2$, phytoene synthase 2 gene; PDS, phytoene desaturase gene; ZDS, $\zeta$-carotene desaturase gene; CRTISO, carotene isomerase gene; $L C Y$ - $E$, lycopene $\varepsilon$-cyclase gene; $L C Y-B$, lycopene $\beta$-cyclase gene; $C Y P 97-A 29$, cytochrome $\mathrm{P} 450$ a cyclohydroxylase gene; $C Y P 97-C 11$, cytochrome P450 \& cyclohydroxylase gene; $C R T R-B 1$, beta-carotene hydroxylase 1 gene; $C R T R-B 2$, beta-carotene hydroxylase 2 gene; $Z E P$, zeaxanthin epoxidase gene; $V D E$, violaxanthin de-epoxidase gene

出, 在 4 和 $-4{ }^{\circ} \mathrm{C}$ 败藏第 7 天时表达量分别比败藏初期上 调28.0和23.9倍, 说明枸杞果实在收获后仍进行着活跃 的类胡萝卜素的合成和积累, 并且 $4^{\circ} \mathrm{C}$ 败藏条件更利于 类胡萝卜素合成基因的表达.

类胡萝卜素合成途径下游 $\beta$-胡萝卜素分支途径的合 成酶包括: 番茄红素 $\beta$ 环化酶(LCY-B)、有色体特异的番 茄红素 $\beta$ 环化酶 (CYC-B)、 $\beta$-胡萝卜素羟化酶(CRTRB)、玉米黄素环氧化酶(ZEP)和紫黄质脱环氧酶
$(\mathrm{VDE})^{[20]}$. 由图2可以看出, $4^{\circ} \mathrm{C}$ 贮藏条件下 $L b L C Y E$ 、 $L b L C Y B 、 L b C Y C B 、 L b C R T R-B 1 、 L b C R T R-B 2$ 表达量均 高于 $-4^{\circ} \mathrm{C}$. 其中 $L b L C Y B 、 L b C Y C B$ 作为分支上游的两个 关键酶在它藏第 7 天时其基因表达量均显著上调 $(P<0.01)$, 与负藏初期 $\beta$-胡萝卜素和玉米黄质含量升高相 一致(图1).

玉米黄素是 $\beta$-胡夢卜素分支合成途径的中间物质. 一方面主要酯化合成玉米黄素双棕㭣酸酯, 另一方面 
又可在玉米黄素环氧化酶(ZEP)的作用下氧化为视紫 黄质, 玉米黄素的积累受多个酶调控. 如图2, LbZEP和 $L b V D E$ 在穴藏14 21 d显著上调表达，并且 $4^{\circ} \mathrm{C}$ 条件下 表达量高于 $-4^{\circ} \mathrm{C}$. 这与枸杞果实玉米黄素含量的变化 趋势相同.

上述结果表明，参与类胡萝卜素合成的基因在穴 藏过程中总体上呈现上调表达的趋势，与玉米黄素及 玉米黄素双棕㭣酸酯含量的总体变化趋势一致，但与 不同败藏温度下各种类胡萝卜素组分、含量的变化趋 势不符说明类胡萝卜素积累不仅取决于合成相关酶基 因的表达，还受到类胡萝卜素存储和降解相关酶基因 的共同调控.

\section{3 类胡萝卜素存储相关酶基因表达}

类胡萝卜素的积累不仅与合成速率有关，还与体 内质体结构和存储相关蛋白基因的表达水平有关. 鲜 枸杞穴藏期间有色体特异的类胡萝卜素结合蛋白 (CHRC)、热激蛋白(HSP) 和橙色类胡萝卜素蛋白 OR1、OR2基因表达总体呈上调趋势, 并且, $-4^{\circ} \mathrm{C}^{\circ}$ 藏 条件下枸杞果实类胡萝卜素存储相关基因的表达量显 著高于 $4^{\circ} \mathrm{C}$ (图3)．特别是在穴藏期第14 21天上调最为
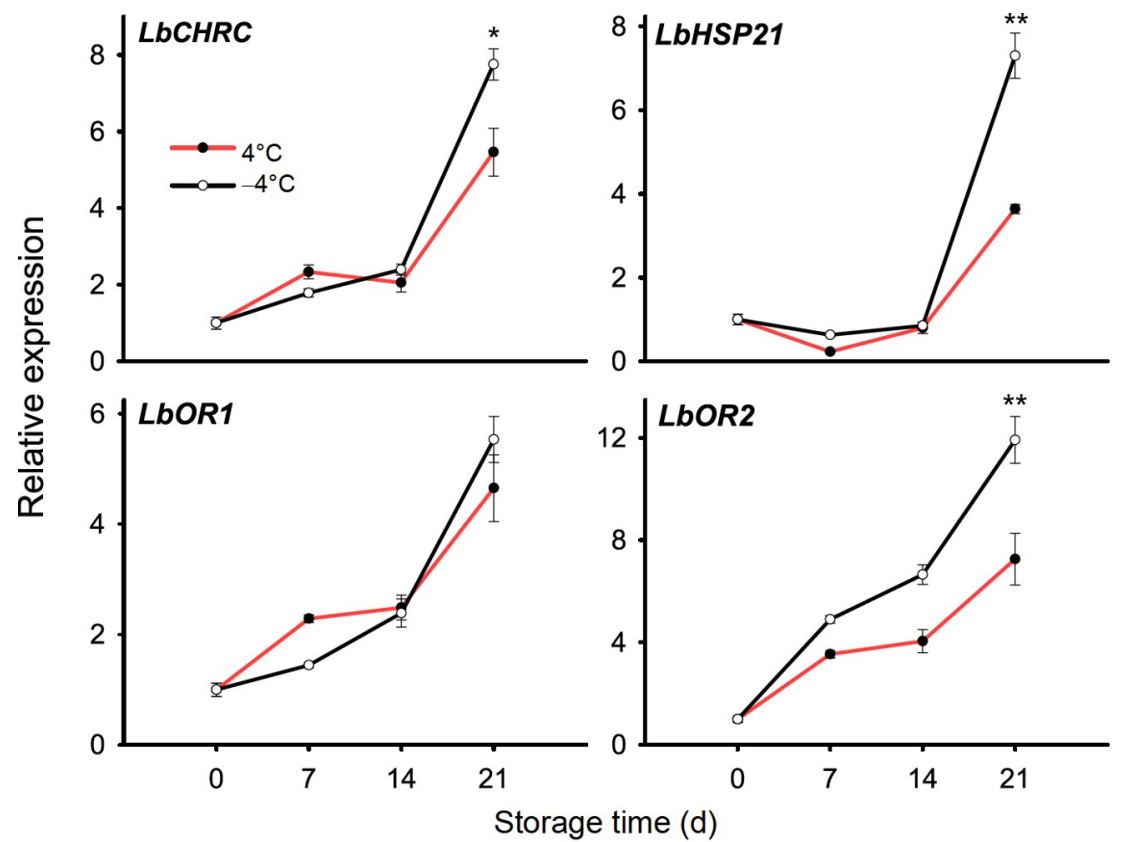

图 3 (网络版彩色)不同㫐藏温度鲜枸杞类胡萝卜素存储基因的表达. CHRC, 有色体特异的类胡萝卜素结合蛋白基因; HSP21，热激蛋白21基 因; OR1, 橙色类胡萝卜素蛋白1基因; OR2, 橙色类胡萝卜素蛋白2基因

Figure 3 (Color online) Gene expression of carotenoid storage protein in fresh Goji berry during storage at different temperatures. CHRC, chromoplast-specific carotenoid-associated protein gene; $H S P 21$, heat shock protein 21 gene; OR1, orange carotenoid protein 1 gene; OR2, orange carotenoid protein 2 gene
显著 $(P<0.01)$. 这一变化趋势与枸杞果实总类胡萝卜素 含量在败藏末期显著上升 ${ }^{[17]}$ 以及 $-4^{\circ} \mathrm{C}$ 败藏条件下类胡 萝卜素含量高于 $4^{\circ} \mathrm{C}$ (图1)的结果相一致.

\section{4 类胡萝卜素降解相关酶基因表达} noid cleavage dioxygenase, CCD)催化降解为脱辅基类 胡萝卜素(apocarotenoid)。虽然目前CCD酶降解类胡萝 卜素的具体机制尚不清楚, 但是现有证据表明, $\mathrm{CCD}$ 家 族基因对类胡夢卜素积累可能具有重要调控作用 ${ }^{[21]}$. 枸杞低温贮藏过程中 LbNCED1、LbNCED6、LbCCD1 和 $L b C C D 4$ 均显著上调表达; $4^{\circ} \mathrm{C}$ 败藏 $7 \mathrm{~d} ， L b C C D 1$ 、 $L b C C D 4$ 和 $L b N C E D$ 6表达量达到高峰，尤其是 $L b C C D 4$ 表达量比败藏前提高 70 多倍, $-4^{\circ} \mathrm{C}$ 伧藏也提高了近 30 倍(图4).

\section{5 氨基酸代谢相关基因表达}

氨基酸是枸杞果实的主要营养成分，同时也是重 要的功效成分, 其种类和含量决定果实营养品质和药 用价值. 我们前期在枸杞中共检测到 23 种游离氨基酸, 总氨基酸含量约为 $9.607 \pm 0.5 \mathrm{mg} / \mathrm{g}$ ，必需氨基酸的含量 类胡萝卜素可被类胡萝卜素裂解双氧化酶(carote- 


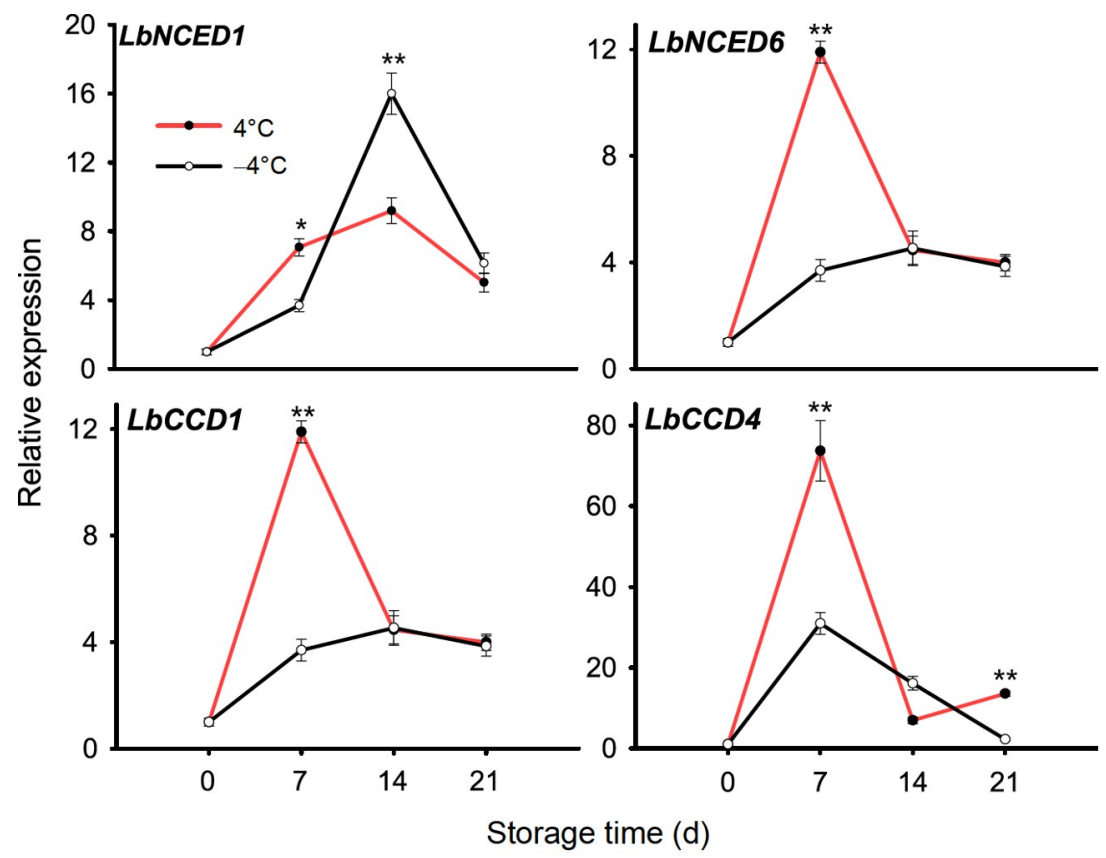

图 4 (网络版彩色)不同则藏温度鲜枸杞类胡夢卜素降解酶基因的表达. $L b N C E D 1$, 环氧类胡夢卜素双氧化酶1基因; LbNCED6, 环氧类胡萝卜 素双氧化酶6基因; $L b C C D 1$, 类胡萝卜素裂解双氧化酶基因; $1 L b C C D 4$, 类胡夢卜素裂解双氧化酶4基因

Figure 4 (Color online) Gene expression of carotenoid degrading enzyme in fresh Goji berry during storage at different temperatures. LbNCED1, 9cis-epoxycarotenoid dioxygenase 1 gene; LbNCED6, 9-cis-epoxycarotenoid dioxygenase 6 gene; LbCCD1, carotenoid cleavage dioxygenase 1 gene; $L b C C D 4$, carotenoid cleavage dioxygenase 4 gene

约为 $0.58 \pm 0.03 \mathrm{mg} / \mathrm{g}^{[17]}$. 在 $4^{\circ} \mathrm{C}$ 栬藏过程中, 总游离氨基 酸含量和必需氨基酸含量较为恒定. $-4^{\circ} \mathrm{C}$ 䛎藏 $7 \mathrm{~d}$, 总氨 基酸含量和必需氨基酸含量均显著增加, 说明 $-4{ }^{\circ} \mathrm{C}$ 捾 藏条件下有利于枸杞果实游离氨基酸的积累.

植物脯氨酸主要通过谷氨酸和鸟氨酸这两条途径 合成, 其中 $\triangle 1$-二氢吡咯-5-羧酸合成酶(P5CS)和鸟氨 酸转氨酶(OAT) 分别是这两条途径中的关键限速酶. 脯 氨酸脱氢酶(ProDH)催化脯氨酸的分解代谢, 在脯氨酸 降解中起重要作用 ${ }^{[22]}$. 由图 5 可知, LbP $5 C S$ 在两个咜藏
温度下的表达趋势不同, 在 $4^{\circ} \mathrm{C}$ 败藏条件下先升高后降 低, 而在 $-4^{\circ} \mathrm{C}$ 它藏条件下随着时间的延长持续增加. $4^{\circ} \mathrm{C}$ 穴藏条件下 $L b O A T$ 表达量始终显著高于 $-4^{\circ} \mathrm{C}$, 但 是 $-4^{\circ} \mathrm{C}$ 条件下 $L b$ ProD $H$ 的表达量则极显著高于 $4^{\circ} \mathrm{C}$ $(P<0.01)$. 结合枸杞穴藏期间氨基酸组分和含量变化的 结果, 说明 $4^{\circ} \mathrm{C}$ 低温咜藏上调 $L b O A T$ 表达、维持 $L b P r o D H$ 在较低水平, 因而有利于脯氨酸的积累.

天冬氨酸激酶 $(\mathrm{AK})$ 是赖氨酸、苏氨酸等合成途径 中的关键酶，受到代谢产物赖氨酸与苏氨酸的协同抑
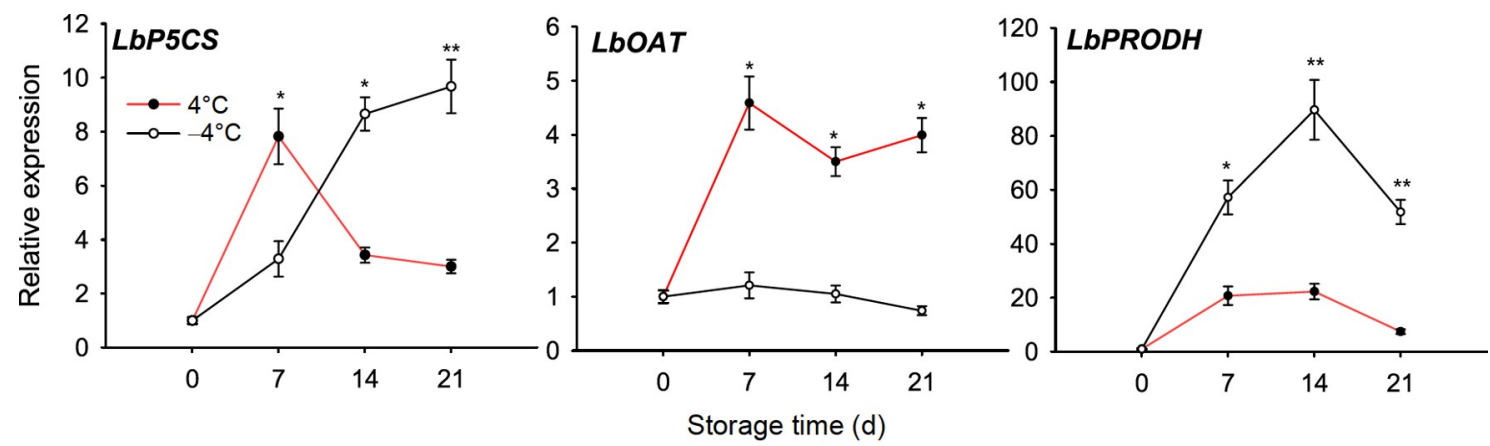

图 5 (网络版彩色)不同穴藏温度鲜枸杞脯氨酸代谢酶基因的表达. P $5 C S, \triangle 1$-二氢吡咯-5-羧酸合成酶基因; $O A T$, 鸟氨酸转氨酶基因; ProDH, 脯氨酸脱氢酶基因

Figure 5 (Color online) Gene expression of proline metabolism enzyme in fresh Goji berry during storage at different temperatures. P5CS, $\triangle-1$ dihydropyrrole-5-carboxylic acid synthetase gene; $O A T$, ornithine aminotransferase gene; ProDH, proline dehydrogenase gene 
制. 天冬氨酸激酶(AK)催化天冬氨酸磷酸化产生天冬 氨酰磷酸, 后者在天冬氨酸半醛脱氢酶(ASADH)催化 下转变成天冬氨酸半醛; 天冬氨酸半醛分别在高丝氨 酸激酶(HK)和其他合成酶的催化进一步合成苏氨酸、 赖氨酸等 ${ }^{[23]}$. 由图6可知, $L b A K$ 在整个只:藏过程中表达 持续增加. $L b A S A D H$ 和 $L b H K$ 表达先升后降, $-4^{\circ} \mathrm{C}$ 伧藏 的枸杞果实在 $7 \mathrm{~d}$ 达到峰值, 而 $4^{\circ} \mathrm{C}$ 咜藏的枸杞果实在第 $14 \mathrm{~d}$ 达到峰值 $(2.94 \pm 0.37)$. 与苏氨酸和赖氨酸的含量增 加相一致.

苯丙氨酸解氨酶(PAL)和肉桂酸-4-差基化酶 $(\mathrm{C} 4 \mathrm{H})$ 是苯丙氨酸代谢途径中的限速酶 ${ }^{[24]}$. 在 $4^{\circ} \mathrm{C}$ 栬藏条件下 $L b P A L$ 表达水平持续下降, 在 $-4^{\circ} \mathrm{C}$ 条件下其表达跌宕起 伏. $\mathrm{LbC} 4 \mathrm{H} 1$ 表达在整个䛎藏过程中呈上升趋势, 并且 4 和 $-4{ }^{\circ} \mathrm{C}$ 之间无显著性差异(图7).

\section{3 讨论}

枸杞鲜果采后梡藏期短是限制产业发展的瓶颈问
题. 低温是延缓生鲜产品衰老劣变、延长其败藏寿命 最安全有效的技术手段. 类胡萝卜素种类和含量是决 定枸杞果实色泽、品质的关键因素. 宁夏枸杞中主要 的类胡夢卜素成分为玉米黄素双棕㭣酸酯、玉米黄素 和 $\beta$-胡萝卜素 ${ }^{[25,26]}$. 本研究表明，枸杞果实中富含玉米 黄素双棕㭣酸酯(含量超过 $85 \%$ ),$-4^{\circ} \mathrm{C}$ 䛎藏显著增加枸 杞果实玉米黄素双棕㭣酸酯的积累; 作为玉米黄素双棕 桐酸脂合成的前体物质，玉米黄素和 $\beta$-胡萝卜素在 $-4^{\circ} \mathrm{C}$ 度败藏条件下积累相对较多或者降解相对延缓, 有利于

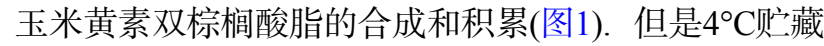
条件却更有利于多数类胡萝卜素合成关键酶基因的表 达(图2), 说明类胡萝卜素在植物体内的积累是一个动态 变化的过程, 受合成、降解以及存储等多方面因素共同 调控(图8). 在 $-4^{\circ} \mathrm{C}$ 聍藏条件下, 枸杞果实类胡夢卜素存 储关键基因 $L b C H R C 、 L b O R 2 、 L b H S P 21$ 的表达量显著 高于 $4^{\circ} \mathrm{C}($ 图3). 此外, 以 $L b C C D 4$ 为代表的类胡萝卜素降 解酶在枸杞果实类胡萝卜素合成与积累调控中扮演着
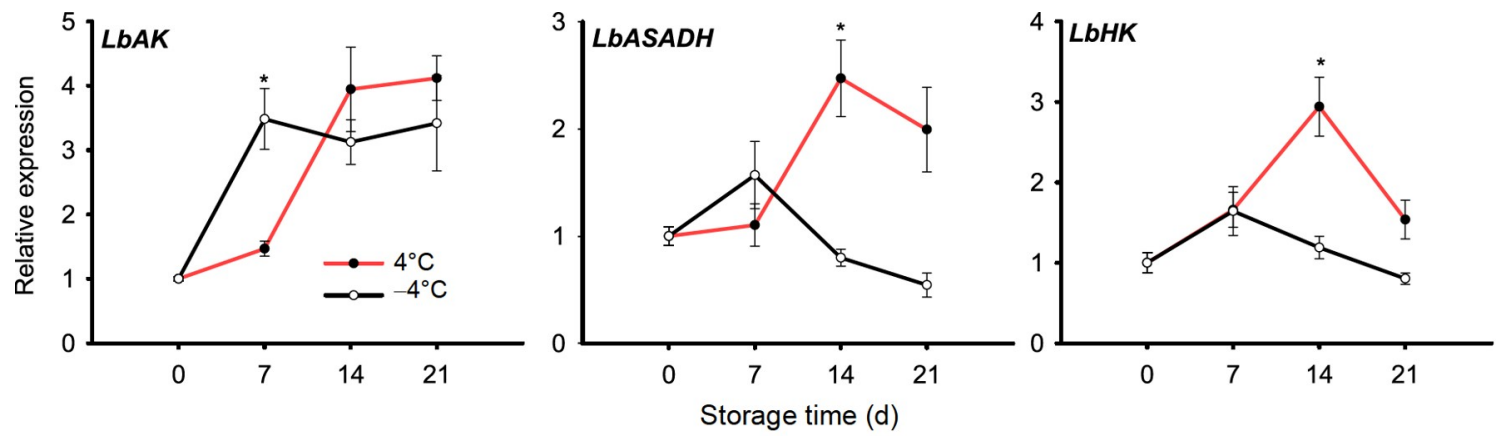

图 6 (网络版彩色)不同败藏温度鲜枸杞天冬氨酸代谢酶基因的表达. $A K$, 天冬氨酸激酶基因; $A S A D H$, 天冬氨酸半醛脱氢酶基因; $H K$, 高丝氨 酸激酶基因

Figure 6 (Color online) Gene expression of aspartic acid metabolism enzyme in fresh Goji berry during storage at different temperatures. $A K$, aspartate kinase gene; $A S A D H$, aspartate semialdehyde dehydrogenase gene; $H K$, homoserine kinase gene
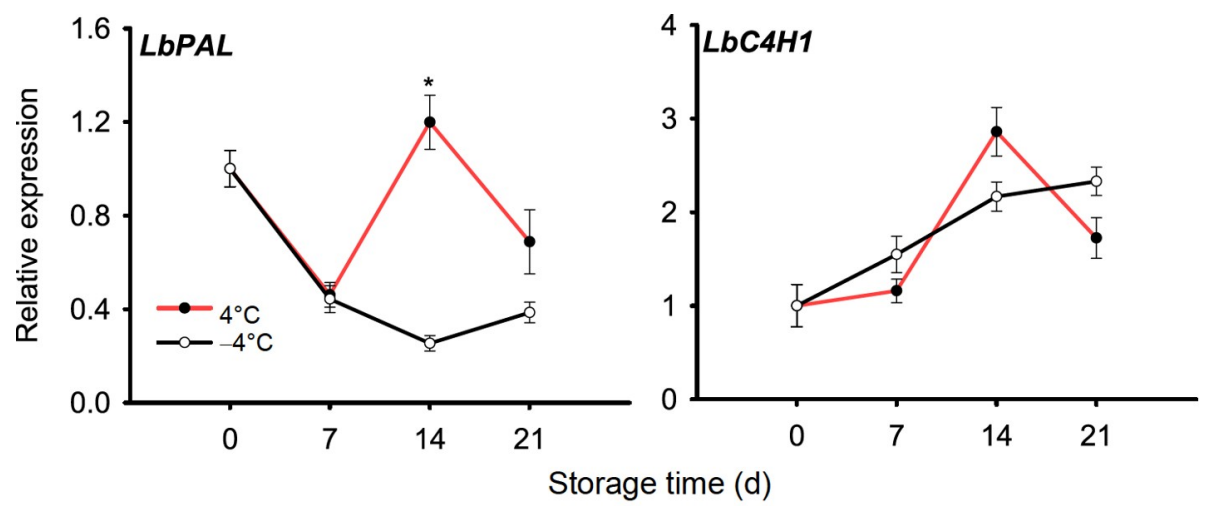

图 7 (网络版彩色)不同只藏温度鲜枸杞苯丙氨酸代谢酶基因的表达. $P A L$, 苯丙氨酸解氨酶基因; C4H1, 肉桂酸-4-差基化酶基因

Figure 7 (Color online) Gene expression of phenylalanine metabolism enzyme in fresh Goji berry during storage at different temperatures. $P A L$, phenylalanine ammonia lyase gene; $C 4 H 1$, cinnamic acid-4-hydroxylase 1 gene 


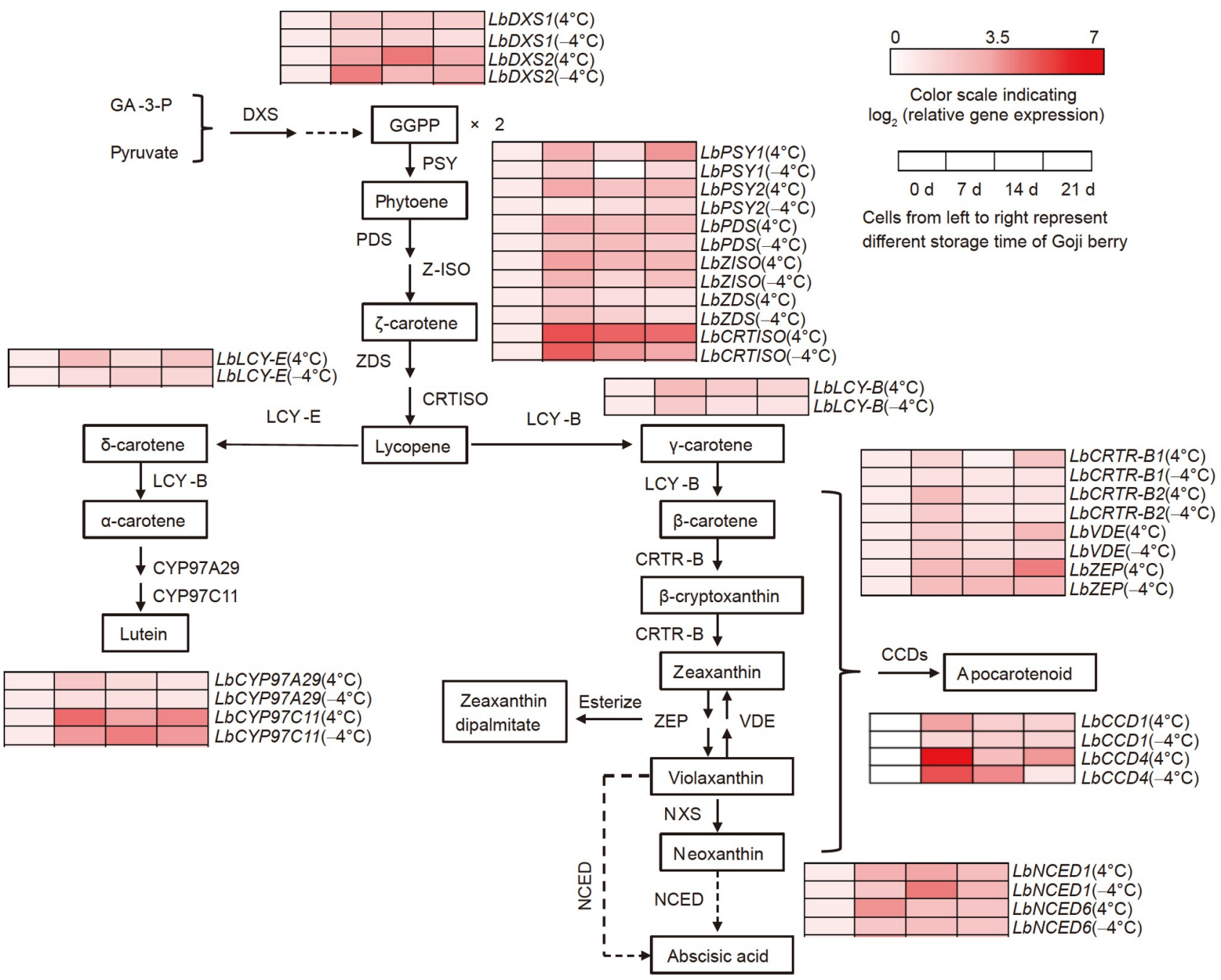

图 8 (网络版彩色)枸杞类胡萝卜素合成、降解通路图. 热图表示枸杞类胡萝卜素合成、降解通路相关基因在采后贮藏0、7、14、21 d时表达 水平的变化, 取 $\log _{2}$ (基因相对表达量)绘制热图; GA-3-P, 3-磷酸甘油醛; pyruvate, 丙酮酸; GGPP, 翇牛儿掂牛儿基焦磷酸; phytoene, 八氢番茄红 素; $\zeta$-carotene, $\zeta$-胡萝卜素; lycopene, 番茄红素; $\delta$-carotene, $\delta$ 胡萝卜素; $\alpha$-carotene, $\alpha$-胡萝卜素; lutin, 芦丁; $\gamma$-carotene, $\gamma$-胡萝卜素; $\beta$-carotene, $\beta$ 胡 夢卜素; $\beta$-cryptoxanthin, $\beta$-隐黄质; zeaxanthin, 玉米黄素; zeaxanthin dipalmitate, 玉米黄素双棕梱酸酯; violaxanthin, 紫黄质; neoxanthin, 新黄素; abscisic acid, 脱落酸; apocarotenoid, 脱辅基类胡萝卜素

Figure 8 (Color online) Schematic of carotenoid biosynthesis and degradation pathways in Goji berry. The heat map shows expression levels of genes articipate in carotenoid biosynthesis and degradation pathways of Goji berry stored for $0,7,14$ and $21 \mathrm{~d}$, respectively. $\log _{2}$ (relative gene expression) was used to draw the graph; GA-3-P, glyceraldehyde-3-phosphate; GGPP, geranylgeranyl diphosphate

极其重要的角色，黑果枸杞中 $L b C C D 4$ 异常高表达被认 为是其无法积累类胡萝卜素、最终呈现黑色的主要因 素 ${ }^{[18]} .4^{\circ} \mathrm{C}$ 咜藏条件下类胡萝卜素降解途径的关键基因 LbNCED6、LbCCD1、LbCCD4表达量显著高于 $-4{ }^{\circ} \mathrm{C}$, 特别是 $L b C C D 4$ 在 4 和 $-4^{\circ} \mathrm{C}$ 陉藏 $7 \mathrm{~d}$ 表达量分别比新鲜采 收时提高 70 和 30 倍(图4). 上述结果说明, 虽然 $4^{\circ} \mathrm{C}$ 败藏 的枸杞果实类胡萝卜素合成基因表达量较高，有利于 类胡萝卜素的合成，但类胡萝卜素存储基因的下调表 达和降解基因的超高表达显著影响其积累. 同时, $-4{ }^{\circ} \mathrm{C}$
条件枸杞类胡萝卜素的存储相关基因表达增加，使得 枸杞类胡萝卜素含量的增加有稳定的保障(图3).

天冬酰胺、丙氨酸和脯氨酸是枸杞果实中含量最 高的 3 种氨基酸. 低温它藏使脯氨酸合成相关的 $L b P 5 C S$ 和 $L b O A T$ 基因表达水平持续上调，但维持脯氨酸降解 相关的 $L b P r o D H$ 在较低水平, 从而有利于脯氨酸的积 累(图 5); $4^{\circ} \mathrm{C}$ 穴藏条件下 $L b O A T$ 表达量始终显著高于 $-4^{\circ} \mathrm{C}$, 但是 $L b \operatorname{Pro} D H$ 的表达量则极显著低于 $-4{ }^{\circ} \mathrm{C}$ $(P<0.01)$, 从而导致脯氨酸大量积累 ${ }^{[15]}$. 同时, 天冬氨 
酸激酶基因 $L b A K$ 的持续高表达则有利于天冬酰胺的 合成和积累(图6). 在 $-4^{\circ} \mathrm{C}$ 条件下, $L b C 4 H 1$ 随着贮藏时 间的延长逐渐升高(图7), 与果实中苯丙氨酸含量的变 化趋势一致.

综上所述，枸杞在采后咜藏过程中类胡夢卜素和 氨基酸的组分和含量均发生动态变化，这些变化不仅 受到内部的基因表达调控还受到外界温度的影响. $4^{\circ} \mathrm{C}$ 穴藏条件下枸杞果实类胡萝卜素裂解酶基因 $L b C C D 4$ 的超高表达和存储蛋白基因的低水平表达，可能是其
类胡萝卜素含量低于 $-4^{\circ} \mathrm{C}$ 败藏的主要原因.

结合咜藏过程中枸杞类胡萝卜素含量的变化认为, $4^{\circ} \mathrm{C}$ 败藏7 $\mathrm{d}$ 时，枸杞积累较多的玉米黄素、 $\beta$-胡萝卜素 和玉米黄素双棕榈酸酯，此时食用可能对人体更有益. $-4^{\circ} \mathrm{C}$ 低温败藏则有利于延缓脯氨酸积累，并且 $-4^{\circ} \mathrm{C}^{\circ}$ 藏 $^{-}$ 14 21 d积累较多的玉米黄素、 $\beta$-胡萝卜素和玉米黄素 双棕㭣酸酯. 生产上可以根据设备和物流运输条件, 采用 $4^{\circ} \mathrm{C}$ 败运结合气调和包装等手段进一步改善鲜枸杞的外 观品质和口感, 从而满足鲜枸杞物流保鲜的技术需求.

\section{参考文献}

1 Luo Q, Cai Y, Yan J, et al. Hypoglycemic and hypolipidemic effects and antioxidant activity of fruit extracts from Lycium barbarum. Life Sci, 2004, 76: 137-149

2 Xiao J, Gao H, Zhou Z Q, et al. Recent progress in the study of zeaxanthin dipalmitate (in Chinese). Chin Sci Bull, 2017, 62: 1691-1698 [肖佳, 高 吴, 周正群, 等. 枸杞属中枸杞红素类成分研究进展. 科学通报, 2017, 16: 1691-1698]

3 Karioti A, Bergonzi M C, Vincieri F F, et al. Validated method for the analysis of Goji berry, a rich source of zeaxanthin dipalmitate. J Agric Food Chem, 2014, 62: 12529-12535

4 Xiao J, Wang J, Xing F, et al. Zeaxanthin dipalmitate therapeutically improves hepatic functions in an alcoholic fatty liver disease model through modulating MAPK pathway. PLoS One, 2014, 9: e95214

5 Liu Y, Zeng S, Sun W, et al. Comparative analysis of carotenoid accumulation in two Goji (Lycium barbarum L. and L. ruthenicum Murr.) fruits. BMC Plant Biol, 2014, 14: 269

6 Guo M, Shi T, Duan Y, et al. Investigation of amino acids in wolfberry fruit (Lycium barbarum) by solid-phase extraction and liquid chromatography with precolumn derivatization. J Food Compos Anal, 2015, 42: 84-90

7 Yang C X. Study on the difference of amino acid content between Chinese wolfberry and red wolfberry (in Chinese). Food Res Dev, 2017, 38: 3437 [杨春霞. 黑果枸杞与红果枸杞氨基酸含量的差异性研究. 食品研究与开发, 2017, 38: 34-37]

8 Wu G Y. Amino acids: Metabolism, functions, and nutrition. Amino Acids, 2009, 37: 1-17

9 Azevedo R A, Arruda P, Turner W L, et al. The biosynthesis and metabolism of the aspartate derived amino acids in higher plants. Phytochemistry, 1997, 46: 395-419

10 Baldwin I T, Kessler A, Halitschke R. Volatile signaling in plant-plant-herbivore interactions: What is real? Curr Opin Plant Biol, 2002, 5: 351-354

11 Gonda I, Bar E, Portnoy V, et al. Branched-chain and aromatic amino acid catabolism into aroma volatiles in Cucumis melo L. fruit. J Exp Bot, 2010, 61: 1111-1123

$12 \mathrm{Hu}$ Y F, Hu H Y, Jiang C J, et al. The influence of different product process on the effect ingredient content of Ningxia Lycium barbarum. Adv Mat Res, 2011, 204-210: 2083-2086

13 Potterat O. Goji (Lycium barbarum and L. chinense): Phytochemistry, pharmacology and safety in the perspective of traditional uses and recent popularity. Planta Med, 2009, 76: 7-19

14 Jatoi M A, Jurić S, Vidrih R, et al. The effects of postharvest application of lecithin to improve storage potential and quality of fresh Goji (Lycium barbarum L.) berries. Food Chem, 2017, 230: 241-249

15 Cuadra-Crespo P, del Amor F M. Effects of postharvest treatments on fruit quality of sweet pepper at low temperature. J Sci Food Agric, 2010, 90 : $2716-2722$

16 Díaz-Pérez J C, Muy-Rangel M D, Mascorro A G. Fruit size and stage of ripeness affect postharvest water loss in bell pepper fruit (Capsicum annuит L.). J Sci Food Agric, 2007, 87: 68-73

17 Li X. Effects of low temperature on the nutritional quality and carotenoid metabolism of wolfberry fruit (in Chinese). Master Dissertation. Guangzhou: Jinan University, 2018 [李新. 穴藏温度对鲜枸杞营养品质及类胡萝卜素代谢的影响. 硕士学位论文. 广州: 暨南大学, 2018]

18 Liu Y L. Virus-induced gene silencing method and comparative analysis of carotenoid accumulation in fruits of Lycium barbarum L. and Lycium ruthenicum Murr. (in Chinese). Doctor Dissertation. Beijing: University of Chinese Academy of Sciences, 2014 [刘永亮. 宁夏枸杞和黑果枸杞中 VIGS技术及果实中类胡夢卜素差异积累的分子机制研究. 博士学位论文. 北京: 中国科学院大学, 2014]

19 Hannoufa A, Hossain Z. Regulation of carotenoid accumulation in plants. Biocatal Agric Biotechnol, 2012, 1: 198-202 
20 Hirschberg J. Carotenoid biosynthesis in flowering plants. Curr Opin Plant Biol, 2001, 4: 210-218

21 Ohmiya A. Carotenoid cleavage dioxygenases and their apocarotenoid products in plants. Plant Biotechnol, 2009, 26: 351-358

22 Deng F F, Yang S L, Gong M. Regulation of proline metabolism by cellular signaling molecules under abiotic stress (in Chinese). Acta Physiol, 2015,10: 1573-1582 [邓凤飞, 杨双龙, 龚明. 细胞信号分子对非生物胁迫下植物脯氨酸代谢的调控. 植物生理学报, 2015, 10: 1573-1582]

23 Yu Y, Song W C, Liu C Y, et al. Research progress on key enzyme genes of plant aspartic acid metabolism pathway (in Chinese). Biotechnol Bul, 2008, S1: 7-11 [于妍, 宋万冲, 刘春燕, 等. 植物天冬氨酸代谢途径关键酶基因研究进展. 生物技术通报, 2008, S1: 7-11]

24 Li L, Zhao Y, Ma J L. The key enzymes of phenylalanine metabolism: PAL, C4H, 4CL (in Chinese). Bioinformatics, 2007, 4: 187-189 [李莉, 赵 越, 马君兰. 苯丙氨酸代谢途径关键酶: PAL, C4H, 4CL研究新进展. 生物信息学, 2007, 4: 187-189]

25 Tang W M, Chan E, Kwok C Y, et al. A review of the anticancer and immunomodulatory effects of Lycium barbarum fruit. Inflammopharmacology, 2011, 20: 307-314

26 Inbaraj B S, Lu H, Hung C F, et al. Determination of carotenoids and their esters in fruits of Lycium barbarum Linnaeus by HPLC-DAD-APCI-MS J Pharmaceut Biomed Anal, 2008, 47: 812-818

\section{补充材料}

图S1 不同它藏温度鲜枸杞外观品质

表S1 基因qRT-PCR引物

本研究以上补充材料见网络版csb.scichina.com. 补充材料为作者提供的原始数据, 作者对其学术质量和内容负责. 


\title{
Effects of storage temperature on carotenoids and amino acids in fresh Goji berry and the related regulation mechanism
}

\author{
Yijie Zhou ${ }^{1}$, Xin $\mathrm{Li}^{2}$, Sanmei $\mathrm{Ma}^{2}$, Shaohua Zeng ${ }^{1}$, Ying Wang ${ }^{1}$, Yueming Jiang ${ }^{1}$ \& Hongxia $\mathrm{Qu}^{1 *}$ \\ ${ }^{1}$ South China Botanical Garden, Chinese Academy of Sciences, Guangzhou 510650, China; \\ ${ }^{2}$ Department of Bioengineering, Jinan University, Guangzhou 510632, China \\ * Corresponding author, E-mail:q-hxia@scbg.ac.cn
}

Fresh Goji berry has become more and more popular in recent years with consumers' increasing demand for nutritional, healthy, and natural food. However, freshly harvested Goji berry is highly perishable, deteriorating and quickly losing its commercial value in 1-2 $\mathrm{d}$ at room temperature due to its unique structural and biological characteristics (tender, hollow with thin pericarp and high water content). In order to optimize the storage conditions for fresh Goji berry and better retain its nutritional components, Goji berry was stored at 4 and $-4^{\circ} \mathrm{C}$ for up to $21 \mathrm{~d}$. The changes in fruit appearance, the evolution of the contents of zeaxanthin, $\beta$-carotene, and zeaxanthin dipalmitate, and the expressions of genes related to the synthesis, storage, and degradation of carotenoids and those related to the metabolism of amino acids were investigated in the present study. The results showed that the contents of zeaxanthin, $\beta$-carotene, and zeaxanthin dipalmitate were relatively higher in Goji berry stored at $4^{\circ} \mathrm{C}$ for $7 \mathrm{~d}$ or at $-4^{\circ} \mathrm{C}$ for $21 \mathrm{~d}$. As the most characteristic carotenoid in Goji berry, zeaxanthin dipalmitate was $42.14 \%$ higher at $-4^{\circ} \mathrm{C}$ than at $4^{\circ} \mathrm{C}$ at the end of storage. The carotenoid synthesis genes were expressed at higher levels, while the carotenoid storage protein genes, LbHSP21 and LbOR2, were expressed at significantly lower levels at $4^{\circ} \mathrm{C}$. At the same time, the carotenoid cleavage enzyme genes, $L b N C E D 6, L b C C D 1$, and $L b C C D 4$, were expressed at significantly higher levels in Goji berry stored at $4^{\circ} \mathrm{C}$. In particular, the expression level of $L b C C D 4$ on day 7 was 70 and 30 times higher than that on day 0 at 4 and $-4^{\circ} \mathrm{C}$, respectively, which may explain the lower carotenoids contents at $4^{\circ} \mathrm{C}$ by the end of storage.

The expressions of proline synthesis genes, $L b P 5 C S$ and $L b O A T$, increased, while that of proline degradation gene $L b P R O D H$ declined during storage. The expression level of $L b O A T$ was significantly higher, while that of $L b P r o D H$ was significantly lower at 4 than at $-4^{\circ} \mathrm{C}(P<0.01)$, which might facilitate the accumulation of proline in Goji berry stored at $4^{\circ} \mathrm{C}$. At the same time, the continuously higher expression of aspartate kinase gene $L b A K$ was conducive to the synthesis and accumulation of asparagine. The expression of $L b C 4 H 1$ increased gradually during storage, which was consistent with the changing trend of phenylalanine content.

In conclusion, the contents of carotenoids and amino acids in Goji berry changed dynamically during postharvest storage, which were not only regulated by the internal gene expression but also affected by the external environment such as temperature. The results of the present study showed that Goji berry stored at $-4^{\circ} \mathrm{C}$ had higher contents of carotenoids, a lower content of proline, and therefore, a better nutritional quality with postponed senescence and deterioration. The significantly higher expression of $L b C D D 4$ and lower expressions of carotenoid storage protein genes may be the main reason for the lower carotenoids contents at $4^{\circ} \mathrm{C}$ compared with at $-4^{\circ} \mathrm{C}$. The presented study preliminarily elucidated the possible molecular mechanism of why $-4^{\circ} \mathrm{C}$ storage is more conducive to the accumulation of carotenoids and the delay of senescence and deterioration in Goji berry. This study provides new insights for the preservation and circulation of fresh Goji berry in the supply chain.

storage temperature, zeaxanthin dipalmitate, carotenoid, amino acid, metabolism, regulation

doi: 10.1360/TB-2020-1688 